Research Article

\title{
Investigation on the Impacts of COVID-19 Lockdown and Influencing Factors on Air Quality in Greater Bangkok, Thailand
}

\author{
Parichat Wetchayont $(\mathbb{D}$ \\ Department of Geography, Faculty of Social Sciences, Srinakharinwirot University, Bangkok 10800, Thailand \\ Correspondence should be addressed to Parichat Wetchayont; parichatw@g.swu.ac.th
}

Received 27 October 2020; Revised 29 December 2020; Accepted 22 January 2021; Published 4 February 2021

Academic Editor: Ilan Levy

Copyright (c) 2021 Parichat Wetchayont. This is an open access article distributed under the Creative Commons Attribution License, which permits unrestricted use, distribution, and reproduction in any medium, provided the original work is properly cited.

\begin{abstract}
With the outbreak of the COVID-19 pandemic around the world, many countries announced lockdown measures, including Thailand. Several scientific studies have reported on improvements in air quality due to the impact of these COVID-19 lockdowns. This study aims to investigate the effects of the COVID-19 lockdown and its driving influencing factors on air pollution in Greater Bangkok, Thailand, using in situ measurements. Overall, PM2.5, PM10, $\mathrm{O}_{3}$, and $\mathrm{CO}$ concentrations presented a significant decreasing trend during the COVID-19 outbreak year based on three periods: the Before Lockdown, Lockdown, and After Lockdown periods, for PM2.5: $-0.7 \%,-15.8 \%$, and $-20.7 \%$; PM10: $-4.1 \%,-31.7 \%$, and $-6.1 \%$; and $\mathrm{O}_{3}:-0.3 \%,-7.1 \%$, and $-4.7 \%$, respectively, compared to the same periods in 2019. CO concentrations, especially which had increased by $14.7 \%$ Before Lockdown, decreased by $-8.0 \%$ and $-23.6 \%$ during the Lockdown and After Lockdown periods, respectively. $\mathrm{Meanwhile} \mathrm{SO}_{2}$ increased by $54.0 \%, 41.5 \%$, and $84.6 \%$, and $\mathrm{NO}_{2}$ increased by $20.1 \%, 3.2 \%$, and $26.6 \%$, respectively, for the Before Lockdown, Lockdown, and After Lockdown periods. PCA indicated a significant combination effect of atmospheric mechanisms that were strongly linked to emission sources such as traffic and biomass burning. It has been demonstrated that the COVID-19 lockdown did pause some of these anthropogenic emissions, i.e., traffic and commercial and industrial activities, but not all of them. Even low traffic emissions, on their own, did not cause an absolute reduction in air pollution since there are several primary emission sources that dominate the air quality over Greater Bangkok. Finally, these findings highlight the impact of COVID-19 lockdown measures not only on air pollution levels but on their effects on air pollution characteristics, as well.
\end{abstract}

\section{Introduction}

The entire world has been battling with the coronavirus since the first case was reported on December 31, 2019, in Wuhan, China. Ultimately, the coronavirus was declared a pandemic by the World Health Organization (WHO) on March 11, 2020 [1] as COVID-19 spread. As of updated numbers, on December 28, 2020, there were 81,264,631 reported positive cases and 1,774,317 deaths worldwide, including Thailand [2]. Soon after COVID-19 was discovered, lockdown measures and social distancing started being used as a global pandemic action plan to prevent COVID-19 from spreading. In Thailand, government authorities announced COVID-19 prevention and control actions, including lockdown and curfew hours, for the whole country from March 26, 2020, to May 31, 2020. These COVID-19 lockdown measures decreased human activities, especially in the traffic, industrial, and energy production sectors, which assumes a corresponding decrease in anthropogenic emissions of air pollution. Generally, air quality is indicated by several pollutants such as surface ozone $\left(\mathrm{O}_{3}\right)$ levels, emissions of $\mathrm{NO}_{\mathrm{x}}, \mathrm{CO}$, and $\mathrm{SO}_{2}$, and aerosol emissions (PM10 and PM2.5). Many research studies have reported on improvements in air quality due to the effects of COVID-19 lockdown measures [3-7]. For example, Xu et al. [8] indicated that effects of the COVID-19 outbreak presented positive feedback in reductions of average concentrations of atmospheric PM2.5 by $-30.1 \%, \mathrm{PM} 10$ by $-40.5 \%, \mathrm{SO}_{2}$ by $-33.4 \%$, CO by $-27.9 \%$, and $\mathrm{NO}_{2}$ by $-61.4 \%$, respectively, during February 2020 in Central China. Meanwhile, Southeast Asian cities such as Manila, Kuala Lumpur, and Singapore also reported decreasing trends of $\mathrm{NO}_{2}(-27 \%$ to 
$-30 \%)$ and of PM10 (-26 to $-31 \%)$, PM2.5 ( -23 to $-32 \%)$, $\mathrm{NO}_{2}(-63$ to $-64 \%), \mathrm{SO}_{2}(-9$ to $-20 \%)$, and $\mathrm{CO}$ concentrations ( -25 to $-31 \%)$, respectively [9]. In addition, Nadzir et al. [3] found that, in Malaysia, CO dropped by $-48.7 \%$, but PM2.5 and PM10 increased by $60 \%$ and $9.7 \%$, respectively, as their results indicated high AODs from Himawari-8 and $\mathrm{NO}_{2}$ concentrations from Aura-OMI satellite sensors. This was associated with massive biomass burning in northern Thailand and Laos during the Lockdown period (March 2020), which prevented exploration of the impact due to lockdown on air pollution in this region. Most of the research has been performed in the megacities, but Stratoulias and Nuthammachot [10] analyzed concentrations of air pollutants over a medium-sized city (in Songkhla Province) in Southern Thailand and found that concentrations of PM2.5 had changed by $-21.8 \%, \mathrm{PM} 10$ by $-22.9 \%, \mathrm{NO}_{2}$ by $-33.7 \%$, and $\mathrm{O}_{3}$ by $-12.5 \%$ in the first 3 weeks of the lockdown compared to the respective prelockdown period. Kerimray et al. [11] presented the effects of the COVID-19 lockdown during traffic-free conditions in Kazakhstan, with a PM2.5 reduction of $-21 \%$ and other gaseous pollutants down by $-15 \%$ to $-49 \%$. Meanwhile, Filonchyk and Peterson [12] discovered that overall concentrations of air pollutants in Shanghai, China, were reduced during their lockdown period, though they were still higher than the World Health Organization (WHO) guidelines, indicating that there were other significant background sources. Zangari et al. [13] also presented impacts of the lockdown on PM2.5 and $\mathrm{NO}_{2}$ concentrations in New York City, indicating that they had decreased in the short term. However, using a linear time lag model, it indicated that there were no significant concentration changes in the long term. Moreover, Suhaimi et al. [14] suggested that $\mathrm{NO}_{2}$ and ambient temperature were the most significant air pollutant and meteorological factors during the COVID-19 outbreak in Kuala Lumpur.

Recently, Bangkok has experienced winter pollution events with more frequency. Previous studies have mentioned that the most common sources of PM2.5 emissions in Bangkok are from biomass burning, traffic, and industrial activities, with varying concentrations caused by seasonal factors [15-17]. Moreover, Watcharavitoon et al. [18] presented spatial and temporal variation trends of gaseous air pollutant concentrations for $\mathrm{O}_{3}, \mathrm{NO}_{\mathrm{x}}, \mathrm{CO}$, and $\mathrm{SO}_{2}$ from 1996 to 2009 in Bangkok between residential and roadside areas. They reported seasonal trends of gaseous air pollutant concentrations which decreased from January to August and then increased from September to December. Gaseous air pollutant concentrations clearly presented higher concentration levels at the roadside areas than at the residential areas.

Bangkok is a big city, with the 2020 population of the metropolitan area estimated at 10,539,415, with a high number of vehicles estimated at more than ten million (official accumulated number of registered vehicles) in 2020. When the people were largely restricted to their homes, there should have been greater reductions in vehicle emissions during the Lockdown period. And the same should have been true for the industrial sector. However, the COVID-19 lockdown's impact on air quality in Bangkok is currently unknown. Therefore, this study aims to explore the effects and driving influencing factors of the COVID-19 lockdown measures on air quality in Greater Bangkok, Thailand, using in situ measurements with principal component analysis (PCA).

\section{Materials and Methods}

2.1. Study Area. Greater Bangkok refers to Bangkok, the capital, along with the surrounding provinces of Nakhon Pathom, Nonthaburi, Pathum Thani, Samut Prakan, and Samut Sakorn. Greater Bangkok covers an area of $7,762 \mathrm{~km}^{2}$ $(100.20 \mathrm{E}$ to $100.9 \mathrm{E}, 13.0 \mathrm{~N}$ to $14.0 \mathrm{~N})$ and is the center of economic development and an important industrial base for the surrounding provinces (Figure 1). Some industries in Samut Prakan, Samut Sakorn, and Pathum Thani have already become the main emission sources of atmospheric pollution from industry.

\subsection{Ground-Based Air Pollution Monitoring, Traffic Index,} and Fire Spots. Major air pollutants and aerosols including carbon monoxide $(\mathrm{CO})$, ozone $\left(\mathrm{O}_{3}\right)$, nitrogen dioxide $\left(\mathrm{NO}_{2}\right)$, sulfur dioxide $\left(\mathrm{SO}_{2}\right)$, and particulate matter with diameter lower than $10 \mu \mathrm{m}$ (PM10) and $2.5 \mu \mathrm{m}$ (PM2.5) concentration data were collected from the Pollution Control Department (PCD) of Thailand by observing 23 automatic monitoring sites [19]. The monitoring sites were almost all located in the Bangkok metropolitan area, as shown in Figure 1. Data were collected hourly from the period of January 1,2019, to July 20, 2020 , for both aerosols and gaseous pollutants. In addition, the traffic index refers as TI [20] for the same period, as the air pollutant dataset will be used to analyze the emission source from vehicles on the entire road network in Bangkok with a range of 0 to 10 (from free-flow to jam) to link air pollution with people movements. Moreover, in order to relate the emission source with biomass burning, active fire data from satellite observations by the Visible Infrared Imaging Radiometer Suite (VIIRS) were provided through NASA's Fire Information for Resource Management System [21] at the same period as the air pollutants; in this study, it will be referred as the "Fire" factor.

2.3. Meteorological Dataset. It is not only emission sources that influence air quality, but meteorological factors also significantly impact the dilution and accumulation processes of pollutants emitted from local sources [22]. Therefore, to access the variations of air pollutants, meteorological factors must be examined. In this study, meteorological factors were obtained from the ECMWF's fifth-generation Reanalysis (ERA5), the European Centre for Medium-Range Weather Forecasts [23]. The meteorological dataset contains total precipitation (TP), 2-meter air temperature (T2M), planetary boundary layer height (BLH), relative humidity (RH), surface pressure (SP), and wind speed (WS), which have a horizontal resolution of $0.25^{\circ} \times 0.25^{\circ}$ at hourly temporal resolutions for the 2019-2020 period. The meteorological data were picked up at the same hour of the day as the sampling time for the air pollutants. Even though ERA5 data present insufficiency in representing the local meteorology at some monitoring sites, the data resolution seems to be 


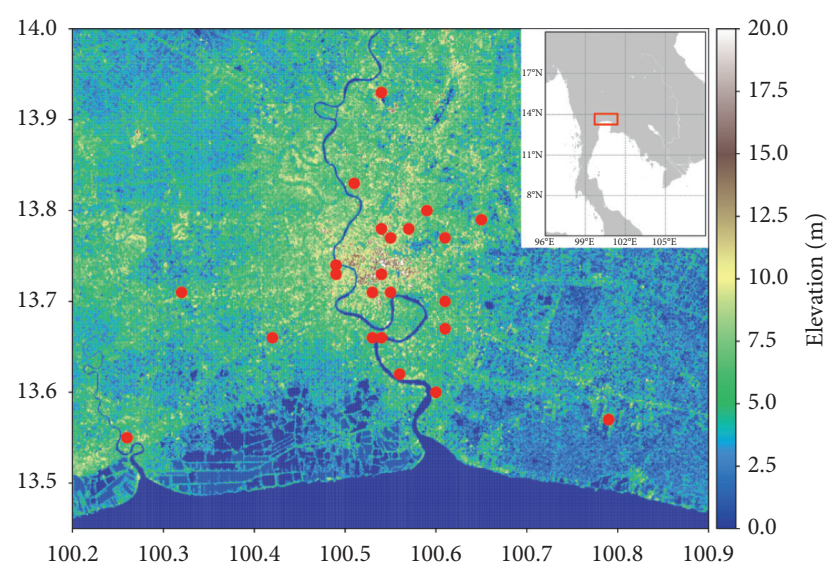

Figure 1: Study area and the 23 PM2.5 automatic monitoring stations in Greater Bangkok, Thailand. The colored bar represents elevation above mean sea level in meters; roads are depicted as straight lines.

applicable, as presented in the previous research for the impacts on meteorology by surface air pollution $[24,25]$.

2.4. Data Analysis Methods. Variations of air quality regarding the COVID-19 outbreak were investigated for three different periods, Before Lockdown (from January 1 to March 25), Lockdown (March 26 to May 31), and After Lockdown (June 1 to July 31 ). To evaluate the impact of COVID-19, the data of the year 2020 were compared to data of the year 2019 at the same period, with the data of the year 2019 being used as the baseline. Changes in the air pollutant levels were evaluated by comparing those 3 different periods in the year 2020 with 2019 at the same time (expressed in \%) between the Before Lockdown, Lockdown, and After Lockdown periods. In order to access the influences between meteorological factors, the air pollutants and other accompanying parameters gave different responses between the three periods associated with the COVID-19 lockdown. We performed data analysis using a principal component analysis (PCA), which is a statistical multivariate analysis for data that features a large variable set. This method enables the researcher to identify correlations and patterns in a dataset by transforming them into a new smaller set of uncorrelated variables, namely, principal components (PCs), which still contain most of the information as the large set [26]. Therefore, by applying a PCA method to air pollutant concentrations and meteorological variables, a dataset could be obtained with the most significant variables, which could indicate the source of the pollutants and largely explain the variations in the air pollution [27]. In this study, the meteorological variables of T2M, SP, TP, RH, WS, and BLH; the major air pollutants: $\mathrm{PM} 10, \mathrm{PM} 2.5, \mathrm{NO}_{2}, \mathrm{SO}_{2}, \mathrm{CO}$, and $\mathrm{O}_{3}$ concentrations; and the anthropogenic activities, TI and Fire, were taken up for analysis. The PCs created by PCA were rotated using an orthogonal rotation method (Vari$\max )$ to compute the explained variance matrix. The numbered PCs were selected according to an eigenvalue greater than or equal to 1 . These PCs are a linear combination of the explanatory variables; therefore, Pearson correlation tests were used to determine the correlation between the PCs and the original variables as a loading factor. Significant variables were identified when the correlation value was greater than or equal to 0.3 .

\section{Results and Discussion}

3.1. The Influence of COVID-19 Lockdown on Variations of Air Qualityover Greater Bangkok. Figure 2 presents a time series of the rolling 24-hour average of daily PM2.5 concentration variations on a daily scale for 23 measurement stations for the periods from March 1 to July 31 of 2019 and 2020 in Greater Bangkok, Thailand. The grey color represents the Lockdown period from March 26, 2020, to May 31, 2020. The concentrations of PM2.5, $\mathrm{PM} 10, \mathrm{NO}_{2}, \mathrm{O}_{3}, \mathrm{SO}_{2}$, and $\mathrm{CO}$ were compared between the 3 different periods: Before Lockdown (January 1-March 1), Lockdown (March 26-May 31), and After Lockdown (June 1-July 31). There were similarly significant seasonal variations in the PM2.5, $\mathrm{PM} 10, \mathrm{NO}_{2}, \mathrm{O}_{3}$, and $\mathrm{CO}$ concentrations, where the highest mean concentrations occurred in January during the Before Lockdown period for Greater Bangkok, then exhibited decreasing concentrations during the Lockdown and After Lockdown periods. While $\mathrm{SO}_{2}$ concentrations show a highly fluctuating time series throughout the year, especially in 2020, there were higher concentration levels and more fluctuation by degree than in 2019. As illustrated in Figure 3, changes in the mean concentration values of six major pollutants during the COVID-19 outbreak reveal that there were no substantial decreases in PM2.5 (-0.7\%), PM10 (-4.1\%), and $\mathrm{O}_{3}$ $(-0.3 \%)$ concentrations during the Before Lockdown period with the previous year. But there were changes in $\mathrm{SO}_{2}$ (54.0\%), $\mathrm{NO}_{2}$ (20.1\%), and $\mathrm{CO}(14.7 \%)$ concentrations during the Before Lockdown period. Meanwhile, there were reductions in concentrations of PM2.5 (equaling -15.8\%), PM10 (-31.7\%), $\mathrm{CO}(-8.0 \%)$, and $\mathrm{O}_{3}(-7.1 \%)$ during the Lockdown period, and PM2.5 (by -20.7\%), PM10 (-6.1\%), $\mathrm{CO}(-23.6 \%)$, and $\mathrm{O}_{3}(-4.7 \%)$ during the After Lockdown period, when compared to the previous year. Stratoulias and Nuthammachot [10] similarly reported a decreasing range in PM2.5 and PM10 concentrations during the Lockdown period. On the other hand, $\mathrm{NO}_{2}$ and $\mathrm{SO}_{2}$ concentrations increased in this study during the Lockdown $(3.2 \%$ and 41.5\%) and in the After Lockdown period (26.6\% and 84.6\%) in 2019 and 2020, respectively. In contrast, Kanniah et al. [9] and Stratoulias and Nuthammachot [10] found that there were decreased concentrations of $\mathrm{NO}_{2}$, according to the Aura satellite in Malaysia and Southern Thailand. Generally, average concentrations of PM2.5, PM10, $\mathrm{NO}_{2}, \mathrm{O}_{3}$, and $\mathrm{CO}$ exhibit a decreasing trend from March to August [18], even in the previous years before the COVID-19 outbreak, as shown in Figure 2, except for $\mathrm{SO}_{2}$. Seasonal variations (summer and rainy seasons), denoted by rising temperatures and more frequent rains, caused decreasing air pollutant concentrations, excluding some periods when the air pollutant concentrations showed several peaks association with open biomass burning and traffic index peaks due to added 


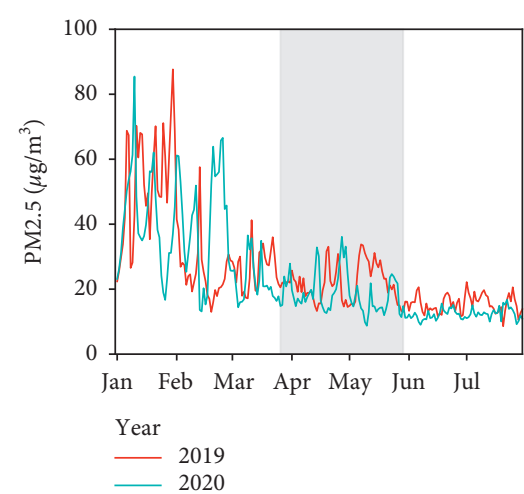

(a)

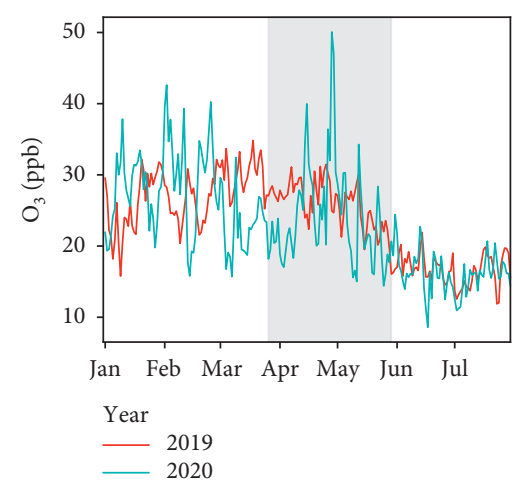

(d)

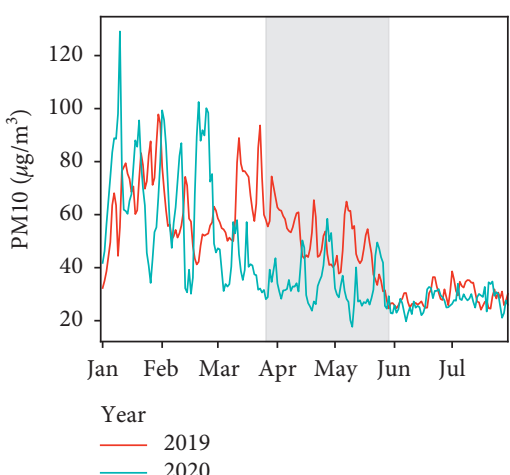

(b)

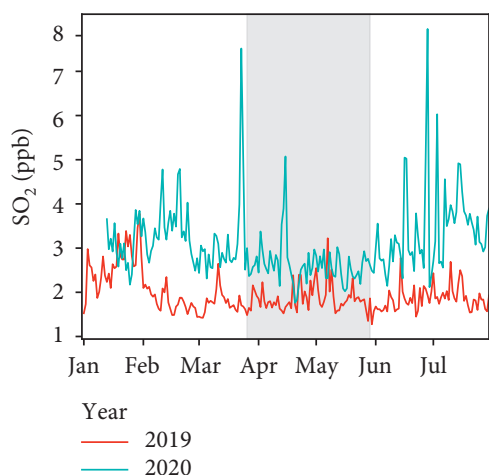

(e)

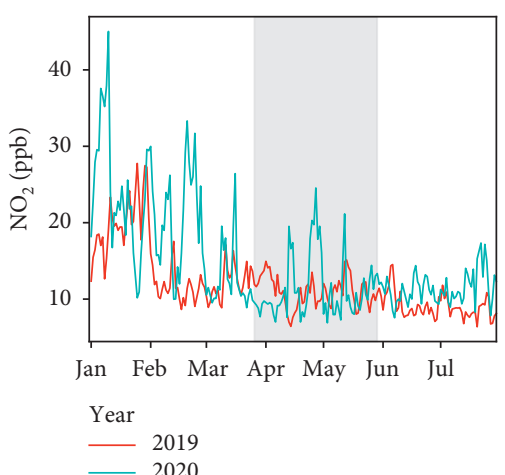

(c)

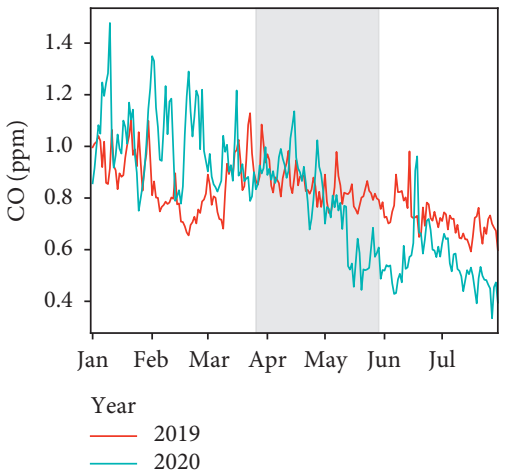

(f)

FIGURE 2: Rolling 24-hour average of hourly air pollutant concentration variations of major air pollutants over 23 ground-based stations in Greater Bangkok for the years 2019 and 2020. Grey color highlights the Lockdown period from March 26, 2020, to May 31, 2020. (a) PM2.5. (b) PM10. (c) $\mathrm{NO}_{2}$. (d) $\mathrm{O}_{3}$. (e) $\mathrm{SO}_{2}$. (f) $\mathrm{CO}$.

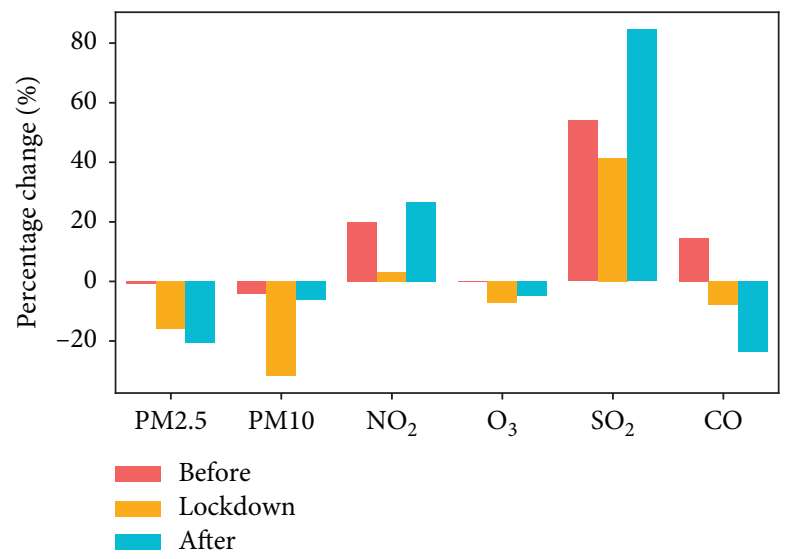

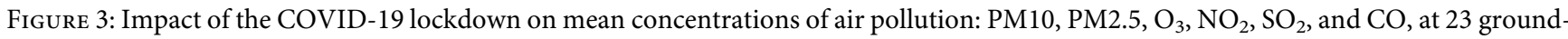
based measurements during the Before Lockdown, Lockdown, and After Lockdown periods in Bangkok, Thailand.

anthropogenic pollutants during the harvest season [28] and road traffic congestion in Bangkok [29].

In principle, air pollutant concentrations in the atmosphere fluctuate because of complex factors such as emission sources (TI and Fire) and meteorological factors (BLH, T2M, TP, WS, and RH) [30]. Anthropogenic sources and meteorological changes during the COVID-19 outbreak period were examined by comparing them with previous years, as shown in Table 1. During the Before Lockdown period, increases were seen in TI (4\%), Fire (26\%), WS (22\%), and RH (14\%), whereas there were decreases in BLH $(-42 \%)$, TP $(-99 \%)$, and T2M $(-5 \%)$. Increased TI and Fire conditions in 2020 may have caused higher $\mathrm{NO}_{2}, \mathrm{SO}_{2}$, and $\mathrm{CO}$ concentrations than in 2019 at the same time. During the first weeks of lockdown, beginning in 2020, there was a sharp decrease in the TI due to limited transportation in Greater Bangkok; after that, the concentrations increased gradually until the end of June (Figure 4(a)). A similar trend was 
TABLE 1: Statistical description of meteorological factors; mean and standard deviation (SD) values in 2019 and 2020 over Greater Bangkok.

\begin{tabular}{|c|c|c|c|c|}
\hline & \multicolumn{2}{|c|}{$\begin{array}{c}\text { Before } \\
\text { Lockdown } 2019\end{array}$} & \multicolumn{2}{|c|}{$\begin{array}{c}\text { Before } \\
\text { Lockdown } 2020\end{array}$} \\
\hline & Mean & SD & Mean & $\mathrm{SD}$ \\
\hline TI & 3.66 & 1.79 & 3.79 & 0.40 \\
\hline Fire (counts/day) & 389.77 & 338.04 & 492.06 & 303.68 \\
\hline SP (mbar) & 1011.86 & 2.25 & 1012.11 & 1.90 \\
\hline $\mathrm{BLH}(\mathrm{m})$ & 511.71 & 428.72 & 295.21 & 160.70 \\
\hline $\mathrm{TP}(\mathrm{mm})$ & 0.03 & 0.18 & 0.00 & 0.01 \\
\hline WS $(\mathrm{m} / \mathrm{s})$ & 13.75 & 11.52 & 16.81 & 11.30 \\
\hline $\mathrm{RH}(\%)$ & 72.72 & 16.44 & 82.84 & 10.14 \\
\hline \multirow[t]{2}{*}{$\mathrm{T} 2 \mathrm{M}\left({ }^{\circ} \mathrm{C}\right)$} & 28.22 & 2.92 & 26.93 & 1.07 \\
\hline & \multicolumn{2}{|c|}{ Lockdown 2019} & \multicolumn{2}{|c|}{ Lockdown 2020} \\
\hline $\mathrm{TI}$ & 3.93 & 1.93 & 3.10 & 0.38 \\
\hline Fire (counts/day) & 80.68 & 81.87 & 164.55 & 326.44 \\
\hline SP (mbar) & 1007.66 & 2.33 & 1009.69 & 1.73 \\
\hline $\mathrm{BLH}(\mathrm{m})$ & 615.80 & 371.17 & 393.45 & 130.12 \\
\hline $\mathrm{TP}(\mathrm{mm})$ & 0.11 & 0.36 & 0.04 & 0.21 \\
\hline WS $(\mathrm{m} / \mathrm{s})$ & 14.77 & 11.33 & 18.64 & 11.30 \\
\hline $\mathrm{RH}(\%)$ & 72.30 & 13.75 & 83.48 & 3.70 \\
\hline \multirow[t]{2}{*}{$\mathrm{T} 2 \mathrm{M}\left({ }^{\circ} \mathrm{C}\right)$} & 30.81 & 2.50 & 28.99 & 1.02 \\
\hline & \multicolumn{2}{|c|}{$\begin{array}{c}\text { After } \\
\text { Lockdown } 2019\end{array}$} & \multicolumn{2}{|c|}{$\begin{array}{c}\text { After } \\
\text { Lockdown } 2020\end{array}$} \\
\hline TI & 4.29 & 1.94 & 3.82 & 0.63 \\
\hline Fire (counts/day) & 8.72 & 8.65 & 7.84 & 7.60 \\
\hline SP (mbar) & 1006.72 & 1.54 & 1007.13 & 2.73 \\
\hline $\mathrm{BLH}(\mathrm{m})$ & 584.75 & 350.74 & 301.21 & 125.16 \\
\hline $\mathrm{TP}(\mathrm{mm})$ & 0.22 & 0.58 & 0.10 & 0.21 \\
\hline WS $(\mathrm{m} / \mathrm{s})$ & 12.74 & 10.70 & 8.66 & 5.67 \\
\hline RH (\%) & 76.81 & 11.25 & 85.30 & 5.29 \\
\hline $\mathrm{T} 2 \mathrm{M}\left({ }^{\circ} \mathrm{C}\right)$ & 29.95 & 2.16 & 27.94 & 0.89 \\
\hline
\end{tabular}

observed for $\mathrm{NO}_{2}$ (Figure 2(c)). As well, Fire (counts per day) within a $240 \mathrm{~km}$ radius of Bangkok city (Figure 4(b)) shows a high number in the first week of the Lockdown period. News reports indicate that there were great wildfires in northern Thailand at that time, which produced tons of aerosols and pollutants [31]. The hourly meteorological data of Greater Bangkok during the study period in 2019 were compared to those in 2020, and the results are shown in Table 1. As indicated in Figures 4(c)-4(h), there was no obvious change during the COVID-19 outbreak in terms of SP, T2M, WS, BLH, and TP from January to March 2020 compared with previous years. Whereas SP and $\mathrm{RH}$ during the Lockdown period were somehow higher than previous years, T2M and BLH were lower than those in previous years. As shown during the After Lockdown period, $\mathrm{RH}$ was higher, while BLH, TP, WS, and T2M were lower compared to previous years. According to the higher influence of longrange transported air masses in 2020 than in 2019, air pollutant levels over Greater Bangkok were affected not only by localization but also by the transport direction of air mass movements, as well. There were different predominant winds between the years 2019 and 2020. During the Lockdown period in 2019 , the predominant winds were from the southwest part of Bangkok, which is a highly polluted area. Those predominant winds shifted to the south during the same time period in 2020, which brought a clean air mass from the Gulf of Thailand into Greater Bangkok, resulting in a decrease in air pollutant concentrations, even if it did not have formal lockdown measures. It should be noted that wind direction is a factor determining air pollutant levels.

It is evident that the lockdown corresponding to COVID-19 has had an effect on average pollutant concentrations because of human activity restrictions since the lockdown measure began on March 26, 2020, in Greater Bangkok. Moreover, higher WS in 2020 could have helped to dilute the pollutant concentrations in the air [32]. In contrast, Kerimray et al. [11] reported no significant change in average PM2.5 concentrations during the COVID-19 lockdown when compared with previous years in Almaty, Kazakhstan. This is possibly because that they had a shorter period of lockdown (March 19, 2020-April 14, 2020) than in Bangkok; thus, the impact of COVID-19 cannot be compared well to Almaty. In addition, it was during the seasonal transition from summer to rainy seasons in Almaty, and PM2.5 concentrations may have been highly influenced by meteorological factors. In the After Lockdown period, there were decreases in both the source and meteorological variables, except for $\mathrm{RH}$, which increased compared with the previous year. In addition, many studies report that $\mathrm{O}_{3}$ concentrations had increasing trends [33-35], while in this study we found decreasing $\mathrm{O}_{3}$ concentrations over Greater Bangkok. $\mathrm{NO}_{2}$ is an oxidation product from nitrogen oxides (NOx) and $\mathrm{O}_{3}$, which is emitted from combustion sources such as vehicle exhaust, industry, power plants, and residential heating [17]. Thus, this decrease in $\mathrm{O}_{3}$ could be due to greater increases in $\mathrm{NO}_{2}$ concentrations. It is noted that ship traffic along the main river in Bangkok, the Chao Phraya River, is an important logistic hub in Greater Bangkok and a significant emission source of $\mathrm{NO}_{2}$ concentrations. The ship traffic was reduced due to the lockdown too, so this also contributed to the reduction of $\mathrm{O}_{3}$ concentrations.

Furthermore, different degrees of reduction in the pollutant concentrations point out that the decreasing pollution levels in three different periods cannot be explained by limited emissions only but depend on meteorological conditions too. To obtain the influence factors driving air quality improvements between expected emission sources, meteorological variables, and these six pollutants during the COVID-19 outbreak, this study used PCA to investigate in more detail, as shown in the following sections.

3.2. Influence Factors Driving the Improvements in Air Quality. In order to clarify what the main influence is between expected emission sources, meteorological parameters and the six pollutants during the COVID-19 outbreak will be explored in this section. To obtain a better understanding and interpretation of the data, the principal components (PCs) were subjected to a Varimax rotation matrix. Only components with an eigenvalue greater than 1 were determined as principal components (grey color), as shown in Table 2. There are five major PCs in each subset period, comprising PC1, PC2, PC3, PC4, and PC5. The percentage of total variance represents how much the proportion of that 


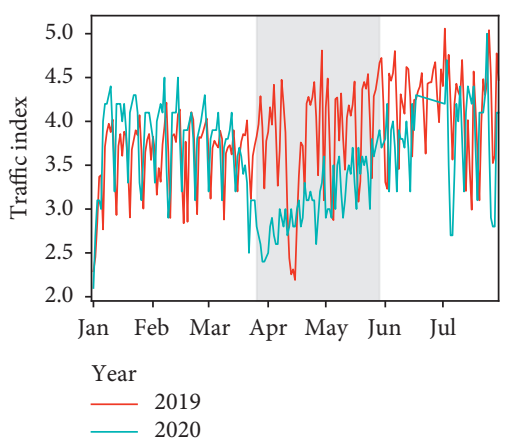

(a)

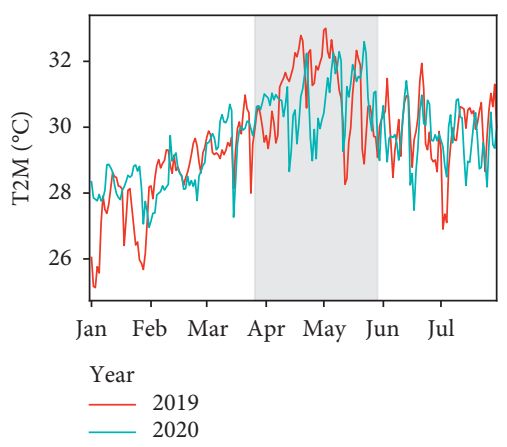

(d)

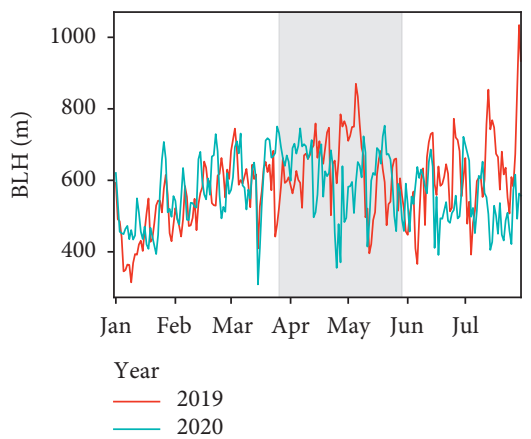

(g)

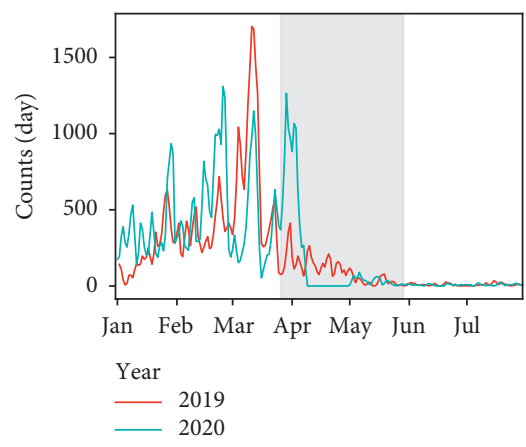

(b)

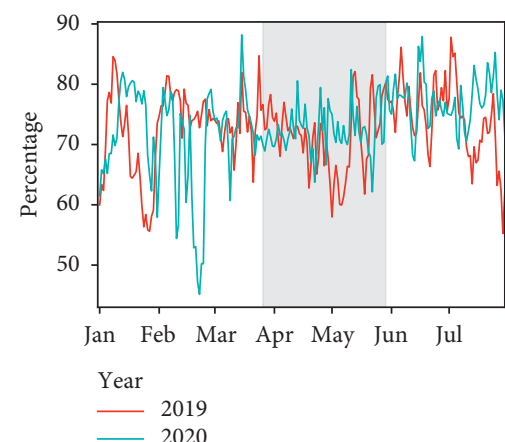

(e)

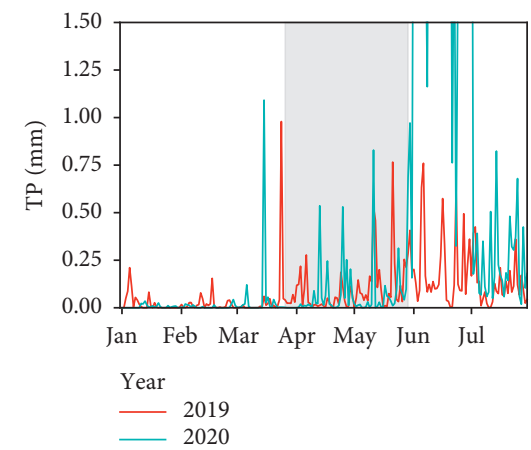

(h)

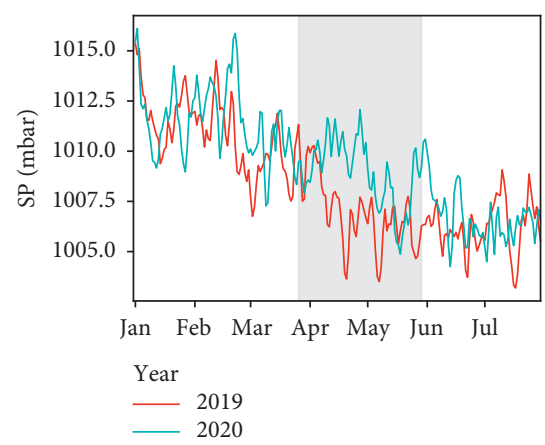

(c)

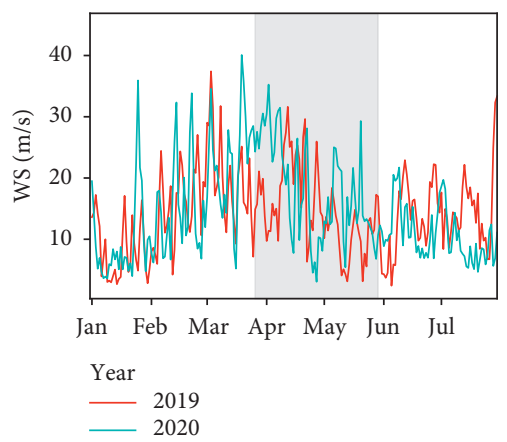

(f)

Figure 4: Temporal variations of the traffic index (a), Fire spot count (b), surface pressure (c), air temperature at 2 meters (d), relative humidity (e), wind speed (f), boundary layer height (g), and total precipitation (h). Grey color highlights the Lockdown period from March 26, 2020, to May 31, 2020. Influence factors driving the improvements in air quality.

PC explains the variation in air quality. In each period of the same year, the percentage of the total variance was slightly different. However, it had some significant differences between the Before Lockdown and the Lockdown periods. To obtain the factor loading, a Varimax rotation with Kaiser normalization (Figure 5) was computed, and a loading factor higher than 0.3 contained from the output becomes a principal component (PC). The results of PCA are summarized in Figure 5, presenting significant PC contributions. A loading factor of more than 0.70 is considered strong, a range of $0.50-0.69$ is considered moderate, and a range of $0.31-0.49$ is considered weak.

During the Before Lockdown period, which denotes the winter season in Thailand, the PC1 and the PC2 could explain the variance by $27.4 \%$ and $18.2 \%$ for 2019 and by $36.7 \%$ and $11.9 \%$ for 2020 , respectively. The results reveal some similarities between these two years, and there were significant mechanisms associated with air quality. $\mathrm{PM} 10, \mathrm{NO}_{2}$, and $\mathrm{CO}$ are dominant pollutant parameters that associate with the particular atmospheric mechanism of low T2M, BLH, and WS and high SP and RH. Hence, these atmospheric mechanisms reduce the ability of the pollutants to disperse from their sources [36]. These pollutants relating to unknown emissions, such as major and traffic-originated emissions, were minor sources in 2019, while in 2020, the major and minor pollutants were related to biomass burning and unknown emission sources, respectively. These results supporting the comparison of concentrations for PM2.5, PM10, and $\mathrm{O}_{3}$ in Section 3.1 between the two years are not significantly different. As mentioned before, the common sources of air pollution in Greater Bangkok are from biomass burning, traffic, and industrial activities, with varying concentrations due to seasonal 
TABLE 2: Total variance explaining the principal components of air pollutants and meteorological elements in 2019 and 2020 over Greater Bangkok.

\begin{tabular}{|c|c|c|c|c|c|c|c|c|c|}
\hline \multirow{2}{*}{$\begin{array}{l}2019 \\
\text { Component }\end{array}$} & \multicolumn{3}{|c|}{ Before } & \multicolumn{3}{|c|}{ Lockdown } & \multicolumn{3}{|c|}{ After } \\
\hline & Eigen value & Variance (\%) & Cumulative (\%) & Eigen value & Variance (\%) & $\begin{array}{c}\text { Cumulative } \\
(\%)\end{array}$ & $\begin{array}{l}\text { Eigen } \\
\text { value }\end{array}$ & $\begin{array}{c}\text { Variance } \\
(\%)\end{array}$ & $\begin{array}{c}\text { Cumulative } \\
(\%)\end{array}$ \\
\hline 1 & 3.84 & 27.40 & 27.40 & 3.50 & 25.00 & 25.00 & 3.58 & 25.60 & 25.60 \\
\hline 2 & 2.55 & 18.20 & 45.60 & 2.32 & 16.60 & 41.60 & 2.21 & 15.80 & 41.40 \\
\hline 3 & 1.22 & 8.70 & 54.40 & 1.34 & 9.50 & 51.10 & 1.44 & 10.30 & 51.60 \\
\hline 4 & 1.08 & 7.70 & 62.10 & 1.28 & 9.10 & 60.30 & 1.34 & 9.50 & 61.20 \\
\hline 5 & 1.02 & 7.30 & 69.30 & 1.14 & 8.10 & 68.40 & 1.16 & 8.30 & 69.40 \\
\hline 6 & 0.83 & 5.90 & 75.30 & 0.98 & 7.00 & 75.40 & 0.87 & 6.20 & 75.70 \\
\hline 7 & 0.82 & 5.80 & 81.10 & 0.77 & 5.50 & 80.80 & 0.84 & 6.00 & 81.70 \\
\hline 8 & 0.66 & 4.70 & 85.80 & 0.64 & 4.60 & 85.40 & 0.57 & 4.10 & 85.70 \\
\hline 9 & 0.61 & 4.40 & 90.10 & 0.58 & 4.20 & 89.60 & 0.53 & 3.80 & 89.50 \\
\hline 10 & 0.45 & 3.20 & 93.40 & 0.46 & 3.30 & 92.80 & 0.45 & 3.20 & 92.70 \\
\hline 2020 & \multicolumn{3}{|c|}{ Before } & \multicolumn{3}{|c|}{ Lockdown } & \multicolumn{3}{|c|}{ After } \\
\hline Component & Eigen value & Variance (\%) & Cumulative (\%) & Eigen value & Variance (\%) & $\begin{array}{c}\text { Cumulative } \\
(\%)\end{array}$ & $\begin{array}{l}\text { Eigen } \\
\text { value }\end{array}$ & $\begin{array}{c}\text { Variance } \\
(\%)\end{array}$ & $\begin{array}{c}\text { Cumulative } \\
(\%)\end{array}$ \\
\hline 1 & 5.15 & 36.70 & 36.70 & 3.58 & 25.50 & 25.50 & 3.25 & 23.00 & 23.00 \\
\hline 2 & 1.67 & 11.90 & 48.60 & 2.20 & 15.70 & 41.20 & 2.43 & 17.20 & 40.20 \\
\hline 3 & 1.22 & 8.70 & 57.30 & 1.84 & 13.10 & 54.20 & 1.68 & 11.90 & 52.10 \\
\hline 4 & 1.09 & 7.80 & 65.10 & 1.61 & 11.50 & 65.70 & 1.62 & 11.50 & 63.60 \\
\hline 5 & 0.96 & 6.80 & 71.90 & 0.99 & 7.00 & 72.80 & 1.15 & 8.10 & 71.70 \\
\hline 6 & 0.89 & 6.40 & 78.30 & 0.85 & 6.10 & 78.80 & 0.87 & 6.10 & 77.90 \\
\hline 7 & 0.86 & 6.10 & 84.40 & 0.74 & 5.30 & 84.10 & 0.80 & 5.70 & 83.60 \\
\hline 8 & 0.60 & 4.30 & 88.70 & 0.57 & 4.10 & 88.20 & 0.61 & 4.30 & 87.90 \\
\hline 9 & 0.48 & 3.50 & 92.20 & 0.47 & 3.30 & 91.50 & 0.52 & 3.70 & 91.60 \\
\hline 10 & 0.43 & 3.10 & 95.30 & 0.41 & 2.90 & 94.40 & 0.42 & 3.00 & 94.50 \\
\hline
\end{tabular}

factors [15-17]. Due to some limitations, emission-related data for the industrial sector were not available for this study. Thus, the unknown emission source might be from industrial or other sources. Moreover, the PC2 in 2019 shows moderate positive contributions of $\mathrm{O}_{3}$ and $\mathrm{T} 2 \mathrm{M}$, which indicates a strong oxidative air condition producing the formation of secondary particles, which could result in a positive loading factor of PM2.5 and $\mathrm{O}_{3}$. As well, in 2020, the PC2 exhibits moderate positive contributions of T2M but negative contributions of $\mathrm{O}_{3}$. This was mainly affected by photochemical reaction. The reaction system can produce $\mathrm{NO}_{2}$ (positive contribution) due to the reaction of $\mathrm{NO}$ with $\mathrm{O}_{3}$ [37]. Additionally, a comparison of the PC1 also explains the increase of $\mathrm{NO}_{2}$ and $\mathrm{CO}$ regarding higher positive contribution magnitudes in 2020 than those in 2019. As well, the PC5 had a higher contribution magnitude for $\mathrm{SO}_{2}$ in 2020 than in 2019, resulting in increased $\mathrm{SO}_{2}$ (Section 3.1).

During the Lockdown period, which denotes the summer season in Thailand, there were significantly different major pollutant parameters contributing to the PC1 (25.0\% and $25.5 \%)$ and PC2 (16.6\% and 15.7\%) for 2019 and 2020 , respectively. In 2019, $\mathrm{O}_{3}$ contributed as a major pollutant ( $\mathrm{PC} 1$ ) corresponding to photochemical reaction $\left(\mathrm{NO}_{2}+\mathrm{O}_{2} \longrightarrow \mathrm{NO}+\mathrm{O}_{3}\right)$, as seen in the strong contribution of T2M with the significant emission source of TI. This explains the correlations with temperature and, partly, with $\mathrm{O}_{3}$ concentrations that are commonly higher in summer [15]. PM2.5, $\mathrm{PM} 10, \mathrm{NO}_{2}, \mathrm{SO}_{2}$, and $\mathrm{CO}$ are minor pollutants (PC2) which relate to unknown emission sources, with the exception of $\mathrm{SO}_{2}$ and $\mathrm{CO}$, which are associated with biomass burning (the PC4). Vice versa in 2020, the increases in PM2.5, PM10, $\mathrm{NO}_{2}$, and $\mathrm{CO}$ concentrations originated from unknown emission sources (PC1), accompanied by strong contributions from decreases in $\mathrm{BLH}$, T2M, and WS. Meanwhile, the moderately negative $\mathrm{O}_{3}$ was related to chemical reaction $\left(\mathrm{NO}+\mathrm{O}_{3} \longrightarrow \mathrm{NO}_{2}+\mathrm{O}_{2}\right)$, becoming a minor mechanism (PC2) corresponding to the $\mathrm{NO}$ added from traffic (TI) and biomass burning (Fire) emissions. These results indicate some important evidence that explains the reduction of air pollutant concentrations in Section 3.1. With COVID-19 lockdown measures, people were largely restricted to their homes, and Greater Bangkok, with its high numbers of vehicles, should have had greater reductions in traffic emissions during the Lockdown period. Decreases in PM2.5, PM10, and CO concentrations in 2020 strongly contributed to the increased Fire (PC1) and the decreased TI (PC2), suggesting that changes in traffic emissions were more responsible for the improvements in air quality during the Lockdown period, especially fine particles, than biomass burning. On the other hand, increases in $\mathrm{NO}_{2}$ concentrations in 2020 (PC2) were significantly related to biomass burning. During the Lockdown period (March 2020), there were massive forest fires in northern Thailand, which reduced the impact of the lockdown on air pollution in that region. A report found an increase in some pollutants during the Lockdown period regarding forest fires in Malaysia [3, 10]. In addition, increased $\mathrm{SO}_{2}$ concentrations were associated with unknown emission sources, which were probably emitted from the industrial sector. 


\begin{tabular}{r|c|c|c|c|c|c|}
\hline $\mathrm{PM} 10-$ & 0.55 & 0.64 & 0.13 & 0.10 & -0.14 & -0.9 \\
$\mathrm{PM} 25-$ & 0.67 & 0.52 & 0.06 & -0.06 & -0.03 & -0.7 \\
$\mathrm{SO}_{2}-$ & 0.28 & 0.16 & 0.39 & -0.32 & 0.48 & -0.5 \\
$\mathrm{NO}_{2}-$ & 0.67 & 0.34 & 0.07 & -0.01 & 0.07 & -0.3 \\
$\mathrm{CO}-$ & 0.48 & 0.39 & -0.03 & -0.44 & 0.28 & \\
$\mathrm{O}_{3}-$ & -0.28 & 0.47 & 0.59 & 0.37 & -0.08 & \\
$\mathrm{TI}-$ & -0.46 & 0.52 & -0.15 & 0.10 & 0.12 & -0.0 \\
$\mathrm{Fire}-$ & -0.36 & -0.21 & 0.26 & -0.45 & -0.04 & \\
$\mathrm{SP}-$ & 0.45 & 0.09 & -0.66 & -0.14 & -0.08 & \\
$\mathrm{BLH}-$ & -0.72 & 0.46 & -0.28 & -0.15 & 0.02 & -0.3 \\
$\mathrm{TP}-$ & -0.02 & -0.08 & -0.22 & 0.48 & 0.77 \\
$\mathrm{WS}-$ & -0.55 & -0.26 & 0.12 & -0.34 & 0.26 \\
$\mathrm{RH}-$ & 0.49 & -0.74 & 0.19 & 0.15 & 0.01 \\
\hline $\mathrm{T} 2 \mathrm{M}-$ & -0.80 & 0.45 & 0.01 & 0.03 & -0.01 \\
\hline
\end{tabular}

(a)

\begin{tabular}{|c|c|c|c|c|c|}
\hline PM10 & -0.03 & 0.70 & -0.14 & -0.09 & -0.09 \\
\hline PM25 & -0.18 & 0.66 & -0.04 & -0.09 & 0.35 \\
\hline $\mathrm{SO}_{2}$ & -0.19 & 0.68 & 0.14 & -0.35 & -0.27 \\
\hline $\mathrm{NO}_{2}$ & -0.26 & 0.56 & 0.39 & 0.20 & 0.31 \\
\hline $\mathrm{CO}$ & -0.06 & 0.52 & -0.00 & -0.22 & -0.39 \\
\hline $\mathrm{O}_{3}$ & 0.46 & 0.23 & 0.21 & 0.64 & -0.18 \\
\hline TI & 0.62 & 0.15 & 0.37 & 0.05 & 0.32 \\
\hline Fire - & 0.21 & 0.28 & -0.71 & 0.37 & -0.05 \\
\hline SP & -0.37 & -0.08 & -0.17 & -0.41 & 0.61 \\
\hline BLH & 0.86 & -0.02 & 0.06 & -0.33 & 0.13 \\
\hline $\mathrm{TP}$ & -0.10 & 0.01 & 0.57 & 0.29 & 0.14 \\
\hline WS & 0.49 & -0.18 & 0.37 & -0.44 & -0.36 \\
\hline $\mathrm{RH}$ & -0.92 & -0.14 & 0.15 & 0.08 & -0.13 \\
\hline $\mathrm{T} 2 \mathrm{M}$ & 0.91 & 0.15 & -0.18 & 0.01 & 0.16 \\
\hline
\end{tabular}

(c)

\begin{tabular}{|c|c|c|c|c|c|}
\hline PM10 & 0.67 & -0.27 & -0.35 & -0.41 & 0.17 \\
\hline PM25 & 0.69 & -0.17 & -0.35 & -0.45 & 0.10 \\
\hline $\mathrm{SO}_{2}$ & 0.07 & -0.23 & -0.33 & -0.03 & 0.71 \\
\hline $\mathrm{NO}_{2}$ & 0.49 & 0.39 & 0.33 & -0.41 & 0.10 \\
\hline $\mathrm{CO}$ & 0.35 & 0.39 & 0.41 & -0.49 & -0.10 \\
\hline $\mathrm{O}_{3}$ & 0.09 & -0.48 & -0.67 & 0.16 & -0.22 \\
\hline TI & 0.11 & -0.71 & 0.47 & 0.17 & 0.09 \\
\hline Fire & -0.37 & 0.63 & -0.26 & -0.12 & 0.24 \\
\hline SP & 0.52 & 0.25 & -0.40 & 0.29 & -0.30 \\
\hline BLH & -0.76 & 0.13 & -0.16 & -0.13 & 0.09 \\
\hline TP & 0.27 & 0.01 & 0.36 & 0.51 & 0.40 \\
\hline WS & -0.73 & 0.32 & -0.34 & -0.06 & 0.11 \\
\hline $\mathrm{RH}$ & 0.44 & 0.43 & -0.05 & 0.53 & 0.17 \\
\hline \multirow[t]{2}{*}{$\mathrm{T} 2 \mathrm{M}$} & -0.69 & -0.50 & 0.19 & -0.33 & 0.04 \\
\hline & PC1 & $\begin{array}{c}1 \\
\text { PC2 }\end{array}$ & $\begin{array}{c}1 \\
\text { PC3 }\end{array}$ & $\begin{array}{l}1 \\
\text { PC4 }\end{array}$ & PC5 \\
\hline
\end{tabular}

(e)

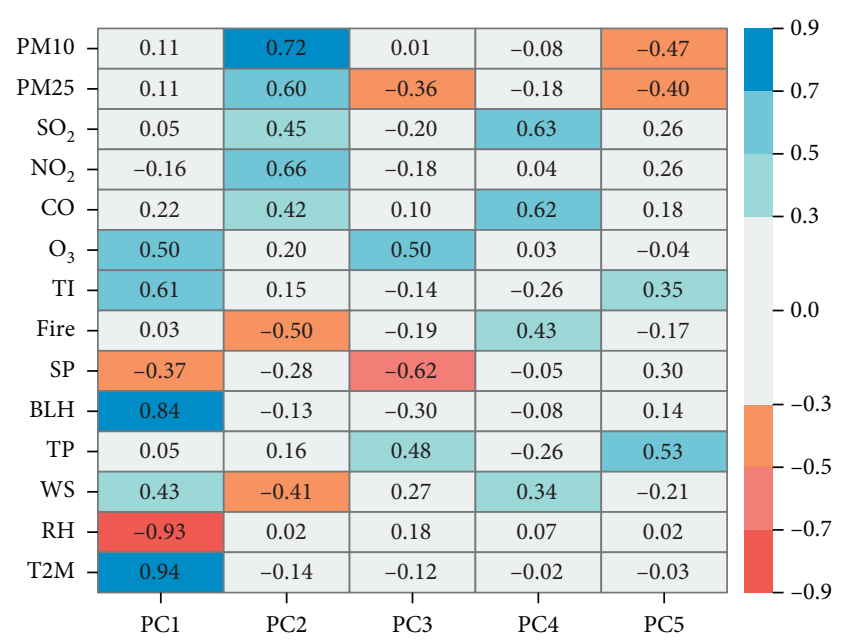

(b)

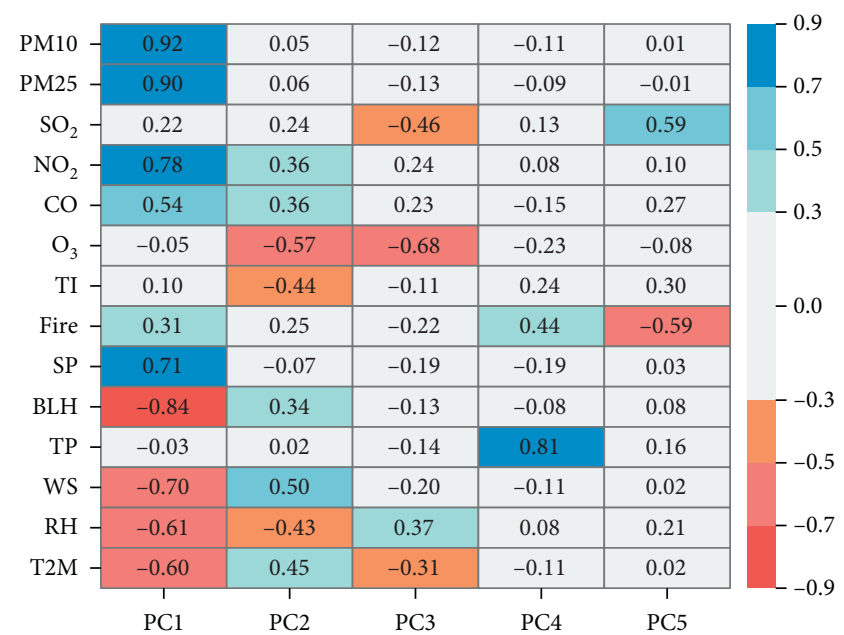

(d)

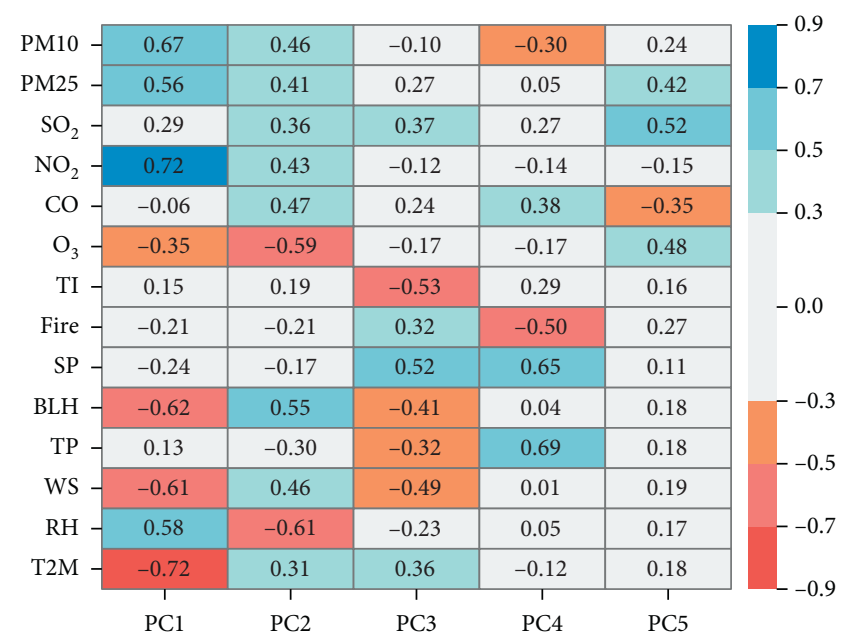

(f)

Figure 5: Loading factors of 14 companies in 5 principal components and their estimated comprehensive eigenvalues. The colored bar represents the level of loading value and numeric shows the component loadings between each meteorological factor and a principal component. (a) Before Lockdown 2019. (b) Lockdown 2019. (c) After Lockdown 2019. (d) Before Lockdown 2020. (e) Lockdown 2020. (f) After Lockdown 2020. 
During the After Lockdown period, which denotes the rainy season in Thailand, the PC1 and the PC2 could explain the variance by $25.6 \%$ and $15.8 \%$ for 2019 and $23.0 \%$ and $17.2 \%$ for 2020 , respectively. In 2019 , there were similar contributions of air pollutants with the Lockdown period in 2020, as seen with increases in $\mathrm{O}_{3}$ concentrations by the production of photochemical reactions being the major mechanism (PC1). Increased PM2.5, PM10, $\mathrm{NO}_{2}, \mathrm{SO}_{2}$, and CO concentrations were minor mechanisms (PC2). In 2020, $\mathrm{PM}$ 2.5, $\mathrm{PM} 10, \mathrm{NO}_{2}, \mathrm{SO}_{2}$, and $\mathrm{CO}$ were major pollutants that originated from unknown sources, with the exception of the PC3, where $\mathrm{SO}_{2}$ concentrations were weakly associated with biomass burning. It can be noted that there were decreases in $\mathrm{BLH}, \mathrm{WS}$, and T2M, which are accumulative atmospheric conditions. Interestingly, there were significant decreases in both TI and Fire, while all pollutants except $\mathrm{O}_{3}$ concentrations had increasing trends. However, as the results in Section 3.1 explain, concentrations of PM2.5, PM10, and CO were still decreased to a lower degree during the After Lockdown period. Therefore, the results demonstrate that the improvement of air quality in Greater Bangkok after the easing of lockdown was a combined effect of other emission sources (industrial, household, etc.) and atmospheric mechanisms.

All PCs during the lockdown of 2020 comprise important evidence that indicates the influence factors driving the improvement of air quality that were affected by the COVID-19 lockdown in Greater Bangkok. Atmospheric mechanisms play an important role in diluting or accumulating pollutant concentrations, while the emission sources influence the concentrations and type of major pollutants. Therefore, the COVID-19 lockdown measures influenced not only the air pollution levels but also affected the air pollution characteristics.

\section{Conclusions}

This study was carried out to expose the effects and influence factors of air quality due to the COVID-19 lockdown in Greater Bangkok, Thailand. Low traffic conditions and reduced human activities due to lockdown measures led to improved air quality in Bangkok. Overall, PM2.5, $\mathrm{PM} 10, \mathrm{O}_{3}$, and $\mathrm{CO}$ concentrations presented a significant decreasing trend during the COVID-19 outbreak year based on three periods: the Before Lockdown, Lockdown, and After Lockdown periods changed by the following amounts: PM2.5 (by $-0.7 \%,-15.8 \%$, and $-20.7 \%$ ); PM10 (by $-4.1 \%,-31.7 \%$, and $-6.1 \%$ ); and $\mathrm{O}_{3}$ (by $-0.3 \%,-7.1 \%$, and $-4.7 \%$ ), respectively. CO increased by $14.7 \%$ and then decreased by $-8.0 \%$ and $-23.6 \%$, respectively, compared to the same periods in 2019 , while $\mathrm{SO}_{2}$ increased by $54.0 \%, 41.5 \%$, and $84.6 \%$ and $\mathrm{NO}_{2}$ went up by $20.1 \%, 3.2 \%$, and $26.6 \%$ during the Before Lockdown, Lockdown, and After Lockdown periods, respectively. PCA was used to explore the influence factors driving improvements in air quality. The results indicate significant combination effects from atmospheric mechanisms that were strongly linked to emission sources such as traffic and biomass burning. Atmospheric mechanisms played an important role in diluting or accumulating the pollutant concentrations, while the emission sources influenced the concentrations and types of major pollutants. However, it was demonstrated that COVID-19 lockdown measures had a significant positive impact on the improvement of air quality due to decreased traffic emissions. With regard to the lockdown measures, they were not restricted by natural disasters such as forest fires in northern Thailand; the pollution from these sources were able to transport to Greater Bangkok, resulting in decreasing magnitudes of the lower pollutant levels recorded in other countries. Furthermore, the results show that after the lockdown was relieved, all pollutants except $\mathrm{O}_{3}$ tended to increase, even though Greater Bangkok's populace still kept to decreased mobility and social activity. This implies that the COVID-19 lockdown was able to pause some anthropogenic emissions, i.e., traffic and commercial and industrial activities, but not all of them. Even low traffic emissions could not absolutely cause a reduction in air pollution since several primary emission sources dominate the air quality over Greater Bangkok. In addition, social distancing guidelines recommended that people stay at home, which caused the consumption of higher electricity, resulting in electric power plants increasing their production capacity and emitting more air pollution. Finally, the results demonstrate that the COVID-19 lockdown measures influenced not only the air pollution levels but also affected the air pollution characteristics.

\section{Data Availability}

The pollution data used in this study were supplied by the Pollution Control Department (PCD) of Thailand under license and so cannot be made freely available. Requests for access to these data should be made to the PCD, http://www. pcd.go.th/.

\section{Conflicts of Interest}

The author declares no conflicts of interest.

\section{Acknowledgments}

The author is sincerely grateful to the Pollution Control Department (PCD) of Thailand for providing PM2.5 concentration data which was used in the study. The author gratefully acknowledges the ECMWF (https://apps.ecmwf.int/ datasets) and Longdo Traffic (https://raffic.longdo.com) for providing the meteorological variable dataset and traffic index, respectively. This work was supported by the Faculty of Social Sciences, Srinakharinwirot University, grant no. 333/2563.

\section{References}

[1] WHO, “Timeline - COVID-19," 2020, https://www.who.int/ news-room/detail/27-04-2020-who-timeline--covid-19.

[2] ECDC, "Download today's data on the geographic distribution of COVID-19 cases worldwide," 2020, https:// www.ecdc.europa.eu/en/publications-data/download-todaysdata-geographic-distribution-covid-19-cases-worldwide.

[3] M. S. M. Nadzir, M. C. G. Ooi, K. M. Alhasa et al., "The impact of movement control order (MCO) during pandemic COVID-19 on local air quality in an urban area of klang 
valley," Malaysia, Aerosol and Air Quality Research, vol. 20, no. 6, pp. 1237-1248, 2020.

[4] R. Bao and A. Zhang, "Does lockdown reduce air pollution? evidence from 44 cities in northern China," Science of the Total Environment, vol. 731, pp. 1-12, Article ID 139052, 2020.

[5] G. Dantas, B. Siciliano, B. B. Franca, C. M. da Silva, and G. Arbilla, "The impact of COVID-19 partial lockdown on the air quality of the city of Rio de Janeiro," Science of the Total Environment, vol. 729, pp. 1-8, Article ID 139085, 2020.

[6] S. Jain and T. Sharma, "Social and travel lockdown impact considering coronavirus disease (COVID-19) on air quality in megacities of India: present benefits, future challenges and way forward," Aerosol and Air Quality Research, vol. 20, pp. 1222-1236, 2020.

[7] L. Li, Q. Li, L. Huang et al., "Air quality changes during the COVID-19 lockdown over the Yangtze River Delta Region: an insight into the impact of human activity pattern changes on air pollution variation," Science of the Total Environment, vol. 732, pp. 1-11, Article ID 139282, 2020.

[8] K. Xu, K. Cui, L.-H. Young et al., "Impact of the COVID-19 event on air quality in central China," Aerosol and Air Quality Research, vol. 20, no. 5, pp. 915-929, 2020.

[9] K. D. Kanniah, N. A. F. Kamarul Zaman, D. G. Kaskaoutis, and M. T. Latif, "COVID-19's impact on the atmospheric environment in the Southeast Asia region," Science of the Total Environment, vol. 736, pp. 1-11, Article ID 139658, 2020.

[10] D. Stratoulias and N. Nuthammachot, "Air quality development during the COVID-19 pandemic over a medium-sized urban area in Thailand," Science of the Total Environment, vol. 746, pp. 1-9, Article ID 141320, 2020.

[11] A. Kerimray, N. Baimatova, O. P. Ibragimova et al., "Assessing air quality changes in large cities during COVID-19 lockdowns: the impacts of traffic-free urban conditions in Almaty, Kazakhstan," Science of the Total Environment, vol. 730, pp. 1-8, Article ID 139179, 2020.

[12] M. Filonchyk and M. Peterson, "Air quality changes in Shanghai, China, and the surrounding urban agglomeration during the COVID-19 lockdown," Journal of Geovisualization and Spatial Analysis, vol. 4, pp. 1-7, 2020.

[13] S. Zangari, D. T. Hill, A. T. Charette, and J. E. Mirowsky, "Air quality changes in New York city during the COVID-19 pandemic," Science of the Total Environment, vol. 742, pp. 1-10, Article ID 140496, 2020.

[14] N. F. Suhaimi, J. Jalaludin, and M. T. Latif, "Demystifying a possible relationship between COVID-19, air quality and meteorological factors: evidence from Kuala Lumpur, Malaysia," Aerosol and Air Quality Research, vol. 20, no. 7, pp. 1520-1529, 2020.

[15] S. Chirasophon and P. Pochanart, "The long-term characteristics of PM10 and PM2.5 in Bangkok, Thailand," Asian Journal of Atmospheric Environment, vol. 14, no. 1, pp. 73-83, 2020.

[16] D. Narita, N. T. K. Oanh, K. Sato et al., "Pollution characteristics and policy actions on fine particulate matter in a growing asian economy: the case of Bangkok metropolitan region," Atmosphere, vol. 10, no. 227, pp. 1-18, 2019.

[17] P. Uttamang, V. P. Aneja, and A. F. Hanna, "Assessment of gaseous criteria pollutants in the Bangkok metropolitan region, Thailand," Atmospheric Chemistry and Physics, vol. 18, no. 16, pp. 12581-12593, 2018.

[18] P. Watcharavitoon, C.-P. Chio, and C.-C. Chan, "Temporal and spatial variations in ambient air quality during 1996-2009 in Bangkok, Thailand," Aerosol and Air Quality Research, vol. 13, no. 6, pp. 1741-1754, 2013.
[19] PCD, "Historical data report," 2020, http://air4thai.pcd.go.th/ webV2/history.

[20] Longdo Traffic, 2020, https://traffic.longdo.com/download.

[21] FIRMS NASA, 2020, https://firms.modaps.eosdis.nasa.gov.

[22] Y. Miao, S. Liu, L. Sheng, S. Huang, and J. Li, "Influence of boundary layer structure and low-level jet on PM2.5 pollution in beijing: a case study," International Journal Environmental Research and Public Health, vol. 16, no. 4, pp. 1-14, 2019.

[23] H. Hersbach, B. Bell, P. Berrisford et al., "The ERA5 global reanalysis," Quarterly Journal of the Royal Meteorological Society, vol. 146, no. 730, pp. 1999-2049, 2020.

[24] E. Boleti, C. Hueglin, S. K. Grange, S. Takahama, and A. S. H. Takahama, "Temporal and spatial analysis of ozone concentrations in Europe based on timescale decomposition and a multi-clustering approach," Atmospheric Chemistry and Physics, vol. 20, no. 14, pp. 9051-9066, 2020.

[25] C. Ordóñez, J. M. Garrido-Perez, and R. García-Herrera, "Early spring near-surface ozone in europe during the COVID-19 shutdown: meteorological effects outweigh emission changes," Science of the Total Environment, vol. 747, pp. 1-10, Article ID 141322, 2020.

[26] S. N. S. A. Mutalib, H. Juahir, A. Azid et al., "Spatial and temporal air quality pattern recognition using environmetric techniques: a case study in Malaysia, (in eng)," Environ Science Process \& Impacts, vol. 15, no. 9, pp. 1717-1728, 2013.

[27] A. Azid, H. Juahir, E. Ezani et al., "Prediction of the level of air pollution using principal component analysis and artificial neural network techniques: a case study in Malaysia, water," Air, \& Soil Pollution, vol. 225, no. 2063, pp. 1-14, 2014.

[28] C. Khamkaew, S. Chantara, S. Chantara, and W. Wiriya, "Atmospheric PM2.5 and its elemental composition from near source and receptor sites during open burning season in chiang mai, Thailand," International Journal of Environmental Science and Development, vol. 7, no. 6, pp. 436-440, 2016.

[29] N. K. Oanh, J. Kongpran, N. T. Hang et al., "Characterization of gaseous pollutants and PM2.5 at fixed roadsides and along vehicle traveling routes in Bangkok Metropolitan region," Atmospheric Environment, vol. 77, pp. 674-685, 2013.

[30] G. Shi, F. Yang, L. Zhang, T. Zhao, and J. Hu, "Impact of atmospheric circulation and meteorological parameters on wintertime atmospheric extinction in chengdu and chongqing of southwest China during 2001-2016," Aerosol and Air Quality Research, vol. 19, no. 7, pp. 1538-1554, 2019.

[31] BangkokPost, "A forest lockdown will fuel more fires," 2020, https://www.bangkokpost.com/opinion/opinion/ 1897615/a-forest-lockdown-will-fuel-more-fires.

[32] D. Hu, J. Wu, K. Tian, L. Liao, M. Xu, and Y. Du, "Urban air quality, meteorology andand traffic linkages: evidence from a sixteen-day particulate matter pollution event in December 2015, Beijing," Journal of Environmental Sciences (China), vol. 59, pp. 30-38, 2017.

[33] P. Sicard, A. De Marco, E. Agathokleous et al., "Amplified ozone pollution in cities during the COVID-19 lockdown," Science of the Total Environment, vol. 735, Article ID 139542, 10 pages, 2020.

[34] S. Sharma, M. Zhang, J. Anshika Gao, H. Zhang, and S. H. Kota, "Effect of restricted emissions during COVID-19 on air quality in India," Science of the Total Environment, vol. 728, 8 pages, Article ID 138878, 2020.

[35] Y. Wang, Y. Yuan, Q. Wang, C. Liu, Q. Zhi, and J. Cao, "Changes in air quality related to the control of coronavirus in China: implications for traffic and industrial emissions," Science of the Total Environment, vol. 731, Article ID 139133, 8 pages, 2020. 
[36] D. Voukantsis, K. Karatzas, J. Kukkonen, T. Räsänen, A. Karppinen, and M. Kolehmainen, "Intercomparison of air quality data using principal component analysis, and forecasting of PM10 and PM2.5 concentrations using artificial neural networks, in Thessaloniki and Helsinki," Science of The Total Environment, vol. 409, no. 7, pp. 1266-1276, 2011.

[37] M. Karl, "Development of the city-scale chemistry transport model citychem-episode and its application to the city of Hamburg," Geoscience Model Development Discussions, vol. $60,2018$. 